\title{
A economia e o turismo em Portugal no pós-crise sanitária: um olhar suportado em dados empíricos e na revisão da literatura
}

\author{
https://doi.org/10.21814/uminho.ed.25.8
}

\section{J. Cadima Ribeiro}

José Cadima Ribeiro (ORCID: 0000-0002-4434-0766) é Professor Catedrático do Departamento de Economia da Escola de Economia e Gestão (EEG) da Universidade do Minho e investigador do NIPE. É doutorado em Ciências Económicas e Empresariais pela Universidade do Minho e autor e coautor de artigos científicos, capítulos de livros e livros nas áreas do desenvolvimento e das políticas regionais e da economia do turismo, entre outras. Desde fevereiro de 2016 é editor-chefe da Revista Portuguesa de Estudos Regionais. 


\section{INTRODUÇÃO}

Nas últimas décadas, o turismo tornou-se uma das atividades que mais tem contribuído para o produto e emprego em muitos países, regióes e cidades em todo o mundo (Folinas e Metaxas, 2020). Esse crescimento extraordinário foi impulsionado por vários fatores ao longo dos anos, principalmente o desenvolvimento de novas tecnologias no âmbito dos transportes e das comunicaçóes, novos estilos de vida decorrentes da crescente prosperidade global e o advento de companhias aéreas de baixo custo, o que tornou as viagens internacionais acessíveis para grandes setores da população mundial. Dados da Organização Mundial do Turismo (OMT) respeitantes ao ano de 2018 mostram que o turismo mundial gerou uma receita de 1.462 bilióes de dólares americanos. Desta, 39\% foi arrecadada pela Europa, que recebeu 51\% do total mundial de turistas (UNWTO, 2020a).

Em razão dessa importância, o impacte da crise sanitária decorrente da doença COVID-19 na economia dos países e territórios mais dependentes da atividade turística tem sido dramática (Gössling, Scott e Hall, 2020; Hall, Scott e Gössling, 2020). No espaço de algumas semanas, alguns destinos evoluíram de uma situação de sobrecarga turística para a ausência de turistas (Gössling, Scott e Hall, 2020). O confinamento das pessoas nas suas residências assim como o fechamento de fronteiras, assumidos como instrumentos centrais do combate à propagação do vírus, podem levar, segundo a UNWTO (2020b), a uma redução entre 20\% e 30\% da receita internacional do turismo (exportaçôes) este ano, em comparação com os valores alcançados em 2019. Isso significaria que, devido à COVID-19, o valor de 5 a 7 anos de crescimento seria perdido (UNWTO, 2020b), sendo esta uma queda maior que as registadas no setor com a crise económica de 2009 e a crise sanitária associada ao vírus SARS (Severe Acute Respiratory Syndrome), em 2003.

Em direta conexão com a crise sanitária que se vive, a estimativa formulada em maio pela Comissão Europeia para a evolução do PIB (Produto Interno Bruto) mundial em 2020 era de $-3,5 \%$, bastante melhor, mesmo assim, do que se previa que acontecesse na União Europeia $(-7,4 \%)$ e, dentro desta, na Zona Euro $(-7,7 \%)$ e em vários países da União, incluindo Portugal (-6,8\%) (GEE, 2020). Por outro lado, os dados divulgados pelo INE (Instituto Nacional de Estatística) referentes ao desempenho da 
economia portuguesa no 1o trimestre de 2020 indicam ter-se verificado uma retração do PIB de 2,4\%, em termos homólogos e que, em março do presente ano, os estabelecimentos hoteleiros acolheram 697,7 mil hóspedes e cerca de 1,9 milhóes de dormidas, refletindo-se tal em variações de $-62,3 \%$ e $-58,7 \%$, respetivamente, face aos dados de fevereiro (INE, 2020a). A mesma instituição (INE, 2020b) divulgou também que, em abril de 2020, o setor do alojamento turístico terá registado 68,0 mil hóspedes e 193,8 mil dormidas, o que corresponde a variações de -97,1\% e -96,7\%, respetivamente, relativamente ao verificado no mês homólogo do ano anterior. As dormidas de residentes terão diminuído $92,7 \%$ ( $-57,6 \%$ em março) e as de não residentes terão decrescido 98,3\% (-59,2\% no mês anterior). Em abril, no contexto do estado de emergência, cerca de $80,6 \%$ dos estabelecimentos de alojamento turístico terão estado encerrados ou não registaram movimento de hóspedes (INE, 2020b).

$\mathrm{Na}$ data antes enunciada (maio de 2020), a Comissão Europeia anunciava previsões de crescimento para 2021 para a economia mundial de 5,2\%, de 6,1\% para a União Europeia a 27 e de 5,8\% para Portugal (GEE, 2020), o que configura a expetativa de uma rápida recuperação, mas que, a confirmar-se, não permitirá repor já no próximo ano a situação em matéria de montante de PIB que se verificava no fecho do ano de 2019. Adicionalmente, vale a pena notar que essa previsão foi feita num cenário de grande incerteza sobre a evolução da crise sanitária e dos seus efeitos nas economias. Estes serão diferenciados em razão da gravidade das situações de saúde experimentadas em cada caso, das estruturas económicas, da capacidade de financiamento das economias e dos seus graus de abertura.

No caso português, em particular, pese o relativo bom desempenho mantido até ao momento na gestão da crise sanitária, importa ter presente a forte dependência que o país mantém da receita turística. $\mathrm{O}$ turismo foi, aliás, um dos principais suportes, senão o principal, da economia nacional durante o período recente de crise da dúvida pública que o país enfrentou, impedindo que PIB e emprego caíssem ainda mais, e foi-o, também, na fase posterior de relançamento económico. Referindo-se a essa realidade de forma crítica, Nunes fala do 'papel predominante` que o turismo teve na economia nacional na última década (Nunes, 2020). 
Do que foi dito antes, resulta claro que o cenário económico do país, da Europa e do mundo nos curto e médio prazos são de grande incerteza económica e insegurança sanitária, condicionando isso projetos e estratégias individuais e coletivos, das famílias às empresas e aos estados. Também por isso é um tempo de desafio e oportunidade, desafio de superação, de procura de novas soluçóes, oportunidade para repensar modelos de organização económica e social e de posicionamento nos mercados, o mercado turístico, entre eles.

Fazendo uso de dados estatísticos e outros recolhidos no âmbito de levantamentos vários que foram sendo realizados para apurar os múltiplos efeitos da crise sanitária provocada pela COVID-19, juntamente com uma revisão de literatura académica no âmbito da economia e do turismo sobre a mesma realidade, faz-se neste capítulo uma reflexão sobre os parâmetros em que se está a tecer a crise social, económica, turística em fase de materialização e sobre o que possa vir a ser a respetiva superação, como e quando. A literatura tomada como foco foi a dos estudos turísticos e "hospitalidade" reportada aos impactes da COVID-19. Sublinhe-se a propósito que vários autores produziram, entretanto, contributos sobre a matéria, muitos dos quais se apesentam ainda em formato de pré-publicação, disponíveis, por isso, apenas em bases de dados de uso dos investigadores.

Dentro desse propósito e com esse suporte, o texto que se segue percorre os 5 tópicos seguintes: i) Incerteza; ii) Insegurança; iii) Assimetria; iv) Reconfiguração e v) Retorno ao caminho. Finaliza com algumas considerações finais onde, entre outras coisas, se sublinha a precaridade de uma análise feita em pleno curso do surto pandémico. Fazendo este percurso, procurar-se-á destacar aquelas que me parecem ser as questões/ preocupaçôes centrais do momento, que se referem ao presente, mas, igualmente, à construção do futuro, apostando num desenvolvimento turístico em Portugal e no Minho, em particular, mais equilibrado e sustentável do que a presente realidade configura.

\section{INCERTEZA}

A crise sanitária, na sua expressão no mundo e implicações de saúde, sociais e económicas, foi/vem sendo um evento absolutamente inesperado e esmagador, que 
poderá ser comparado nas suas repercussóes a tragédias como as da 2a guerra mundial. Em matéria de consequências a nível de saúde coletiva, o paralelo possível de estabelecer será com o surto pandémico que ocorreu entre 2018 e 2020, com origem provável nos Estados Unidos da América, que ficou conhecido como gripe espanhola (Folinas e Metaxas, 2020; Gössling, Scott e Hall, 2020; Hall, Scott e Gössling, 2020; Wanjala, 2020).

Conforme enunciado por Gössling, Scott e Hall (2020), suportados num levantamento da literatura sobre o assunto, a pandemia de 1918 e 1920, levou à infeção de 500 milhões de pessoas (aproximadamente um terço da população mundial) e, segundo estimativas produzidas, resultou na morte de 21 a 100 milhóes de pessoas.

Um fenómeno sanitário com a gravidade e abrangência geográfica da COVID-19 teria que ter um grande impacte económico (Ioannides e Gyimóthy, 2020; Hall, Scott e Gössling, 2020; Ruiz Estrada, Park e Lee, 2020), cujos efeitos se vão estender para além do momento em que a crise sanitária possa ser considerada debelada. Ninguém - indivíduos/famílias, empresas, estados, organizações internacionais - estava preparado para lidar com tal fenómeno e ninguém sabe muito bem o que se vai passar a seguir (Gössling, Scott e Hall, 2020; Ioannides e Gyimóthy, 2020; Ranasinghe, Karunarathna, Pradeepamali, 2020), em que horizonte temporal e como. Daí resulta que estamos perante um cenário de gestão de um fenómeno num contexto de aprendizagem e adaptação/resposta. O planeamento, a decisão e o investimento devem acontecer, mas guiados por esse ambiente de incerteza, o que recomenda muita prudência, e apostas seguras, quer dizer, estruturais.

Num levantamento feito da literatura sobre os impactes económicos de uma crise sanitária, particularmente no turismo, viagens e comércio, Wanjala (2020) apurou que a SARS (Severe Acute Respiratory Syndrome), em 2003, que se estendeu por cerca de 7 meses, provocou efeitos significativos, apesar de se ter saldado num número relativamente pequeno de casos e de mortes. Conforme esperado, uma das áreas mais afetadas foi a do turismo e da indústria de viagens. Os custos foram mais sentidos pelos territórios mais diretamente atingidos, mas não ficaram limitados a esses territórios. Hong Kong, em concreto, decorrente do episódio de saúde antes mencionado, registrou um declínio de $68 \%$ nas chegadas de turistas um mês e meio depois de declarada a epidemia (Wanjala, 2020). 
Uma outra situação também inventariada por Wanjala (2020) foi a epidemia designada internacionalmente por MERS (Middle East respiratory syndrome), que teve origem em Jeddah, na Arábia Saudita e causou um surto em 2015. Apesar de breve, o seu impacte na economia global foi enorme. $\mathrm{Na}$ Coreia do Sul, a doença resultou na colocação de 16.000 pessoas em quarentena, e em 186 infeçôes e 38 mortes. Em matéria de repercussão económica, a epidemia levou a um declínio de $40 \%$ no número de turistas internacionais no primeiro mês e $61 \%$ no segundo mês após a declaração da situação de saúde pública. Por sua vez, a autoridade de turismo da Arábia Saudita estimou que se registou uma perda de receita de 5 bilióes de dólares americanos (EUA) (Wanjala, 2020).

Como quer que seja, nem neste último caso nem no anteriormente referido as crises sanitárias conduziram a uma queda de longo-prazo dos fluxos turísticos globais (Gössling, Scott e Hall, 2020). Isso sugere que o turismo como sistema tem sido bastante resistente a choques externos. No entanto, conforme reclamam Gössling, Scott e Hall (2020), os dados disponíveis no caso da COVID-19 sugerem que o impacte e a recuperação desta pandemia não terão precedente.

Em expressão da incerteza e precariedade trazida pela crise sanitária em curso (COVID-19), mantendo presente o 'papel predominante` que o turismo teve na economia nacional na última década, conforme já mencionado, Nunes (2020) reclama ter-lhe parecido sempre muito questionável económica e politicamente que se defendesse que o turismo constituísse um setor estruturante da economia portuguesa, posto que esta não é uma atividade isenta de fragilidades e que beneficie com a'desordem`. O que Nunes (2020) parece desconsiderar é que, num contexto de economia aberta e de competição aguerrida nos mercados, haverá poucos setores económicos, se é que há algum, que estejam imunes a confrontarem-se com choques externos extremos, em cenários de curto e médio prazos. O que sucedeu em meados da primeira década do século XXI com a fileira do têxtil e vestuário portuguesa, decorrente da integração da China e de outros países asiáticos na Organização Mundial do Comércio como membro de pleno direito, é bem a ilustração disso.

Neste tempo de incerteza, seguro e já bem patente é que temos e iremos experimentar ainda mais perdas de capacidade instalada e destruição de emprego (Gössling, Scott e Hall, 2020; Nunes, 2020; Ranasinghe, Karunarathna, Pradeepamali, 2020; 
Wanjala, 2020), com implicaçôes sociais e económicas que extravasam muito os limites da indústria turística. Isso é assim, tanto assim mais, quanto o turismo é, pela sua natureza, um produto compósito, para o qual contribuem múltiplas atividades e agentes de variados setores, dos transportes e comunicaçóes, à hotelaria e restauração, dos serviços de viagens à cultura e à animação cultural, etc. Em razão disso, em milhares de localidades em todo o mundo, empresas de todos os tamanhos, que dependem direta ou indiretamente do afluxo de visitantes, suspenderam as operaçóes e há indicações de que muitas delas provavelmente nunca irão reabrir (Ioannides e Gyimóthy, 2020). O impacte no mercado de trabalho tem sido devastador, tanto mais que muitos empregos relacionados com turismo e a hospitalidade têm caráter precário e pagam salários baixos (Turismo de Portugal, 2017; Gössling, Scott e Hall, 2020; Ioannides e Gyimóthy, 2020).

Embora seja cedo para prever o impacte total, como se vinha dizendo, podemos observar já algumas das consequências desta crise sanitária, como são reduções drásticas nos processos de produção e consumo e, mais marcadamente, no comércio internacional de bens e serviços e nos fluxos de pessoas (Hall, Scott e Gössling (2020); Olivié e Gracia, 2020), sendo que alguns territórios e setores sociais estão a ser mais duramente atingidos (Ranasinghe, Karunarathna, Pradeepamali, 2020). É expetável que daí decorram efeitos a médio e longo prazos, que não é viável antecipar quais possam ser.

Dado o contexto e implicaçóes mundiais em que a doença decorre, muitas das respostas necessárias só são possíveis de ser dadas e ter alguma eficácia no contexto internacional global, da saúde, à economia e, obviamente, ao turismo, como é sublinhado por Hall, Scott e Gössling (2020), entre outros autores.

Por outro lado, como vem sendo admitido por múltiplos analistas (por exemplo: Olivié e Gracia, 2020), afigura-se como altamente provável assistir-se ao abrandamento do processo de globalização ou mesma a alguma desglobalização, com expressão, nomeadamente, na aposta na reindustrialização em setores considerados estratégicos e, daí, também, à reconfiguração da cadeia de valor em algumas indústrias. A ser assim, o cenário de incerteza que vivemos pode constituir-se num ponto de mudança de projeto económico e social e, porventura, ambiental, igualmente. 
No meio de tanta incerteza e perturbação, fica como consolação (não despicienda), a melhoria significativa a que se assistiu da qualidade do ar, verificada em várias localidades em todo o mundo, com ganhos nessa dimensão que há décadas não se registavam. A redução ou paralisação das viagens locais e internacionais, mas, também, a desaceleração das atividades fabris estarão por detrás desses ganhos (Ioannides e Gyimóthy, 2020; Hall, Scott e Gössling, 2020). Entretanto, a grande questão que se pode colocar é se, passado este momento mais agudo da crise, tudo voltará a ser como antes (Hall, Scott e Gössling (2020), retomando trajetórias de insustentabilidade ambiental reconhecidas, que há muito governos e instituições internacionais, generalizadamente, dizem estar empenhados em mitigar.

\section{INSEGURANÇA}

A insegurança que se vive começa por ser sanitária, sentida por cada um e pelo coletivo, e conduz a insegurança geral, económica, social e turística. Em razão disso, adia-se a retoma da vida económica e social e adiam-se decisões, como a aquisição de certos bens (bens duradouros), o investimento, o planeamento de viagens e o agendamento de férias. Quando não se adiam, avança-se precariamente, ao sabor dos sentimentos e acontecimentos do dia-a-dia, isto é, por exemplo, fazem-se reservas de alojamento para o verão, mas também se cancelam, a seguir, ao menor sinal de incerteza.

Conforme noticiado nos jornais neste final do mês, depois de no dia 14 de abril o primeiro-ministro português, António Costa, ter dito que espera que, no verão, os portugueses tenham possibilidade de gozar férias, as reservas de casas e hotéis no Algarve têm aumentado. O jornal Observador, por exemplo, avançava que os hotéis algarvios estavam a receber cada vez mais reservas, para julho e agosto, de portugueses e turistas estrangeiros, nomeadamente britânicos (ZAP aeiou, de 27 de abril). Entretanto, o diretor da Associação dos Hotéis e Empreendimentos Turísticos do Algarve adiantava que "É verdade que também tivemos e ainda temos muitos cancelamentos" (ZAP aeiou, de 27 de abril). Nesse contexto, o mesmo ator associativo acrescentava nas declarações que fez à comunicação social que "O facto de o Algarve ser considerado um destino turístico COVID-Free pode potenciar o aumento da procura externa” (ZAP aeiou, de 27 de abril). 
Essa leitura de situação aparece confirmada por um estudo realizado junto de agentes de viagens, operadores turísticos e outros profissionais de turismo de Itália, Holanda, França e Espanha, quando interrogados sobre as respetivas visóes sobre as tendências de retoma da atividade, conforme era notícia no sítio da RTBF.be (https:// www.rtbf.be/), em 16 de maio de 2020. De acordo com a notícia publicada e segundo os resultados apurados no inquérito realizado, é expetável que a maioria dos turistas (89\%) imponha a saúde e segurança como prioridades ao escolher o seu destino. Acresce que as viagens (75\%) tenderão maioritariamente a ocorrer nos mercados domésticos e europeu (87\%) e percebidos como menos atingidos pela crise sanitária. É a esta luz que Portugal e Grécia se sugerem ser os grandes ganhadores nesse processo de retoma. Em todo o caso, segundo os mesmos respondentes, deverá demorar algum tempo até se atingir uma situação idêntica à do período anterior à crise (RTBF.be, 2020).

Antes, fez-se referência à probabilidade de se vir a assistir ao abrandamento do processo de globalização ou a alguma desglobalização, cuja expressão concreta é difícil de prever. Importa, no entanto, desde já sublinhar que as consequências e a escala em que as mudanças venham a acontecer, nesta dimensão, também dependem da duração da crise sanitária, com as suas eventuais repetidas vagas e das medidas de "confinamento" que possam continuar a ser tomadas. Infelizmente, uma possível cura, controle ou vacina parece estar ainda muito longe e o período de tempo que tal levará até acontecer ainda é de arriscada previsão (Gössling, Scott e Hall, 2020; Ranasinghe, Karunarathna, Pradeepamali, 2020). Seguro é que se as políticas de liberalização implementadas nas últimas três décadas do século $\mathrm{XX}$ resultaram num rápido crescimento das trocas internacionais (bens, serviços, fluxos de pessoas e de ideias), a severidade da situação ditou a reativação do papel dos Estados e das políticas públicas (Olivié e Gracia, 2020).

Recentrando a abordagem na problemática da indústria turística e tendo presente os dados antes avançados, afigura-se claro que os tempos que vivemos devem ser olhados como oportunidade para repensar as ofertas e a forma como são disponibilizadas, de modo a garantir condições de segurança sanitária fundamentais à recuperação da confiança. 
Os dados antes invocados são corroborados por outros que vão surgindo, de que são exemplo os recolhidos num motor de pesquisa de viagens mencionados num artigo da seção Fugas, do jornal Público, de 28 de março de 2020, onde se reporta que no topo das escolhas de destino apuradas estão as praias e os grandes espaços ar livre, a natureza e, quanto a locais, retendo o caso português, estão os Açores e a Serra da Arrábida (Público, 2020). Perante esses dados, dizia-se, afigura-se claro que os tempos que vivemos devem ser olhados como oportunidade para repensar as ofertas e a forma como são disponibilizadas, de modo a garantir condições de segurança sanitária fundamentais à recuperação da confiança.

Nesse contexto, não sendo expectável que os turistas percam o interesse pelo património e ofertas culturais, incluindo gastronomia e vinhos, que têm sido as grandes alavancas do crescimento da atividade turística nas décadas mais recentes, sobretudo na Europa, é crível que se venham a tornar mais exigentes em matéria de segurança sanitária geral da viagem, dando especial atenção à qualidade do alojamento e do sistema sanitário dos destinos (Soares, Gabriel e Romo, 2020).

\section{ASSIMETRIA}

O que se avançou antes sobre reservas e cancelamentos de férias no Algarve, percebe-se que se passa com outros territórios. Ponte de Lima, por exemplo, é uma das manifestações da assimetria como o fenómeno sanitário, nas suas implicações económicas, se exprime. O Algarve, ao ser considerado um destino turístico COVID-Free, chamemos-lhe assim, pode potenciar a procura externa, na medida em que os seus principais concorrentes se debatem com problemas sérios, a começar pelo sul de Espanha, que é um dos seus maiores concorrentes, segundo o diretor da AHETA (ZAP aeiou, de 27 de abril).

Outra manifestação de assimetria neste fenómeno é a do potencial reforço da procura turística interna, em detrimento da externa, não apenas por razões de confiança mas, igualmente, por determinações administrativas que possam existir (barreiras à circulação de pessoas no contexto internacional) e condicionamentos de transporte (operação das companhias áreas e marítimas, entre outras, que têm sido dos setores 
económicos mais atingidos pela crise económico/sanitária) (Ioannides e Gyimóthy, 2020; Hall, Scott e Gössling, 2020).

Conforme enunciado por Gössling, Scott e Hall (2020) e por Ioannides e Gyimóthy (2020), entre outros investigadores, a evidência inicial dos impactes nas viagens aéreas, cruzeiros e alojamento foi devastadora. A China, onde se originou a doença COVID-19, foi também o primeiro país a sentir as consequências económicas do problema de saúde pública suscitado, não surpreendendo que o turismo tenha sido a principal indústria impactada negativamente. Em concreto, no que se refere à China continental, a maioria das companhias aéreas que aí operavam cancelou os voos de e para a China e todas as atividades turísticas foram interrompidas (Folinas e Metaxas, 2020). Segundo as estimativas de Ruiz Estrada, Park e Lee (2020), no biénio 2020/2021, o setor do turismo chinês pode sofrer uma contração da sua procura em torno dos $75 \%$, a procura externa (comércio internacional) de $40 \%$ e o setor de transporte aéreo de 85\%. Para o mundo, globalmente, embora altamente incertas, as projeçóes iniciais da Organização Mundial do Turismo para 2020 sugerem que as chegadas internacionais podem diminuir de 20 a 30\% face a 2019 (UNWTO, 2020b). Certo parece ser que pode levar bastante tempo até que as viagens de lazer e os voos de longo-curso atinjam os níveis pré-COVID-19 (Ioannides e Gyimóthy, 2020).

Se, como foi dito, parece ser consensual que a crise que enfrentamos terá um grande impacte em todas as dimensões do comércio internacional e que a sua duração é incerta (Olivié e Gracia, 2020), parece ser igualmente seguro que os seus efeitos serão sentidos de forma assimétrica nos diferentes países e territórios. Desde logo, os efeitos económicos tendem a ser especialmente sentidos nas localidades ou mesmo países dependentes fortemente das chegadas de turistas (Ioannides e Gyimóthy, 2020).

Do mesmo modo, os grupos sociais mais pobres e os dependentes de rendimentos associados aos setores mais atingidos pela crise económica serão os mais penalizados (Ranasinghe, Karunarathna, Pradeepamali, 2020). A assimetria decorrerá também das respostas sanitárias e de política económica que forem sendo dadas.

Aparte a queda abrupta ou a paragem dos fluxos turísticos que sucedeu à generalização da crise sanitária, um exemplo de impacte de curto-prazo tornado bem visível 
foi o da queda dramática dos preços do petróleo bruto, que, obviamente, deixou os países produtores em situação difícil (que antes já não era fácil, em particular, em razão da guerra de preços que estava declarada entre a Arábia Saudita e a Rússia). Conforme mencionado por Wanjala (2020), citando (Begley, 2013), a SARS, em 2003, conduziu também a uma queda da procura de petróleo, que se reduziu, em média, em 3.000 barris por dia nos primeiros dois meses da epidemia, tendo tal levado a uma queda nos preços do petróleo em $15 \%$.

No caso do turismo, economias como Espanha, Itália, França, Grécia e Portugal, na Europa e, fora da Europa, Tailândia, Maldivas, Ilhas Seicheles, Ilhas Maurícias, República Dominicana, Bahamas, Camboja, Cabo Verde e Laos, entre muitas outras, com grandes setores de serviços e fortes ênfases no turismo, sofrerão um impacte significativo como resultado da queda de visitantes e das receitas que lhe estariam associadas (Olivié e Gracia, 2020; Ranasinghe, Karunarathna, Pradeepamali, 2020). Por outro lado, sendo sabido que a concentração de pessoas aumenta o potencial de disseminação de doenças por contacto e proximidade, é provável que os maiores centros urbanos e eventos que envolvem maiores volumes de participantes sejam mais penalizados por esta doença (Hall, Scott e Gössling, 2020).

A dimensão já referida de esperada retoma diferenciada no tempo da atividade turística segundo os destinos será também uma das dimensões, porventura a mais sensível, dessa dinâmica desigual que esta crise sanitária está e continuará a ter. Entretanto, a história também dá sustentação à ideia de que as crises também podem desencadear o surgimento de novos modelos de negócios e de oportunidades económicas (Hall, Scott e Gössling, 2020).

\section{RECONFIGURAÇÃO}

A interligação das dimensóes social, cultural, psicológica e económicas de uma crise desta magnitude poderão conduzir ao desenvolvimento de trajetórias imprevistas (Ioannides e Gyimóthy, 2020). Tal pode decorrer do potencial desta pandemia para desencadear mudanças duradouras no comportamento dos indivíduos e das sociedades, que poderá transformar os padróes de consumo turístico e de viagem. Conforme 
sublinhado por Hall, Scott e Gössling (2020), as capacidades transformacionais das pandemias modernas não são nada de novo.

Existindo esse potencial, é também verdade que, no passado, após várias crises sanitárias e económicas que foram sucedendo, a indústria do turismo foi capaz de recuperar, demonstrando um nível de resiliência considerável (Ioannides e Gyimóthy, 2020), embora, muitas vezes, retomando no essencial as linhas de desenvolvimento passadas, isto é, interrompidas. Por exemplo, e conforme sublinharam Zeng, Carter e De Lacy (2005), embora a epidemia de SARS, em 2003, tenha levado a uma significativa queda nas visitas à China, o destino recuperou rapidamente.

$\mathrm{Na}$ expressão vivida inicialmente em matéria de fornecimento de materiais e equipamentos de saúde, mas para além desta, a crise atual destacou o risco de dependência do mercado chinês. Daí poderão resultar estratégias apostadas em diversificar a localização de fornecedores ou em desencadear operaçốes de relocalização (Olivié e Gracia, 2020) e, portanto, contrariar a tendência para o aprofundamento da globalização a que se vinha assistindo.

No quadro do turismo internacional, espera-se, também, que se assista a mudanças que serão desiguais no espaço e no tempo. Nalguns destinos, este quadro económico/sanitário ditará que se reconsiderem a natureza da sua indústria do turismo e se concentrem mais em formas locais e mais sustentáveis de turismo (Gössling, Scott e Hall, 2020; Ioannides e Gyimóthy, 2020; Hall, Scott e Gössling, 2020). Porventura, num primeiro momento, estas estratégias estarão mais atentas ao turismo interno, mas com espaço para a continuação da aposta no turismo internacional.

Em todo o caso, em razão das circunstâncias sem precedentes que o setor de viagens e turismo enfrenta, que também significam, pelo menos a curto-prazo, a redução da atratividade de alguns dos grandes centros urbanos que tradicionalmente atraíam grandes investimentos e número de visitantes internacionais, este parece ser o momento para questionar a sustentabilidade do percurso mantido (Gössling, Scott e Hall, 2020; Ioannides e Gyimóthy, 2020), isto é, para equacionar e pôr no terreno apostas turísticas menos massificados e que vão ao encontro de públicos mais exigentes em matéria de experiência turística. Trata-se de apostar em transformaçôes menos centradas 
no crescimento do número de visitantes e, porventura, mais sustentáveis, nas diversas leituras do conceito, e mais ricas e diversas em matéria de fruição turística e de contributo para o desenvolvimento local, isto é, outros modos de fazer as coisas. Se for esse o caso, sublinha-se, tal abrirá um espaço de oportunidade para regióes menos atraentes e mais escassamente povoadas. Isso poderá criar, também, um cenário em que empresas de menor escala, controladas e operadas localmente, possam reforçar o seu papel no mercado.

Reforça-se, no entanto, que, pese a trajetória de insustentabilidade que foi sendo percorrida por muitos destinos, importa ter presente que o retomar do caminho anterior também se pode configurar, conforme o suporta a evidência histórica (Ioannides e Gyimóthy, 2020; Hall, Scott e Gössling, 2020). O desenvolvimento de nichos como o ecoturismo, o turismo no espaço rural, o enoturismo e o turismo criativo, entre outros, são apostas que fazem particular sentido serem feitas em Portugal. A aposta no património natural e nas manifestaçóes culturais singulares das comunidades, em particular, afigura-se serem uma orientação óbvia pois apresentam baixos riscos de contaminação e a gestão de grupos torna-se mais fácil. De igual modo, e concomitantemente, sugere-se fazer sentido fomentar o turismo em territórios de baixa densidade populacional, o que pode constituir uma real oportunidade para os dinamizar económica e socialmente.

Querendo caminhar para uma oferta menos massificada, mais sustentável e preenchendo requisitos de segurança pessoal em tempos de crise de saúde pública, será necessário qualificar a oferta de modo a proporcionar um bom serviço e suprir as expectativas de um perfil de turista mais exigente (que o vem sendo, cada vez mais, independentemente das circunstâncias) e, desejavelmente, social e ambientalmente mais responsável.

A qualificação da oferta faz-se pela dupla dimensão da identidade/singularidade dos produtos disponibilizados e da qualificação dos prestadores de serviços, onde há espaço significativo para a progredir, como se assumia no documento "Estratégia Turismo 2027” (Turismo de Portugal, 2017). 


\section{RETORNO AO CAMINHO}

Contrariamente ao que acontecia noutros destinos turísticos nacionais, por exemplo, Lisboa, Porto, Algarve e Madeira, o Minho pré-COVID-19 não se tinha tornado num destino massificado. Aparte isso, muita da sua oferta potencial encaixa bem na estratégia que se reclama ser necessário implementar em Portugal no futuro mais próximo e mais longínquo.

As expressões culturais diversas, materiais e imateriais, a natureza, as manifestações particulares do rural, a gastronomia e vinhos, as rotas de peregrinação e de fruição da natureza, etc., são um pano de fundo suficientemente rico e diverso para sustentar um desenvolvimento turístico rico em experiência proporcionada aos visitantes e promotor de desenvolvimento local/regional. A reconfiguração da oferta não parece ser muito difícil de fazer, e as oportunidades económicas avultam. Importa, entretanto, mobilizar os atores convenientes e colocar alguma criatividade para potenciar a atratividade das ofertas e o impacte em matéria de desenvolvimento local.

Entre muitos atributos disponíveis, no Minho encontramos:

i. natureza exuberante, com expressão máxima no Parque Nacional da Peneda Gerês;

ii. festas e romarias de longa tradição (Festas da Senhora da Agonia; Feiras Novas; Festa das Cruzes; etc.);

iii. tradiçôes em matéria de produção de artesanato riquíssimas e diversas, que vão desde os bordados de Viana, aos lenços de namorados, à filigrana, ao figurado em barro e às diversas expressóes do artesanato em barro, onde toma lugar especial o galo de Barcelos, que se presta especialmente para ser usado em materializaçóes de oferta de experiências de turismo criativo;

iv. a gastronomia tradicional, que foi preservada mesmo em tempos de normalização de hábitos de consumo e de banalização de receitas gastronómicas (com pratos como o arroz e as papas de sarrabulho, o bacalhau à Narcisa ou à Braga, a lampreia, o cabrito, a posta barrosã, o pudim Abade de Priscos, etc.);

v. o vinho verde e a respetiva rota gastronómica, onde tomam particular destaque o vinho Alvarinho e os municípios ribeirinhos e fronteiriços de Monção e Melgaço; 
vi. o Caminho de Santiago, com as suas rotas Central e Litoral, atravessando lugares com paisagens urbanas e rurais minhotas tradicionais e permitindo o contacto com as rotinas de vida das gentes minhotas;

vii. o património monumental, do casario urbano medieval (com destaque para o Centro Histórico de Guimarães, por ostentar o título de Património Cultural da Humanidade), aos solares minhotos, às catedrais, aos complexos religiosos (importando realçar o Bom Jesus do Monte, em Braga, por ostentar o título de Património Cultural da Humanidade) e às capelas múltiplas, dispersas no território e às edificaçôes nobres do presente, o Estádio Municipal de Braga, entre elas;

viii. as manifestações e procissóes religiosas, com realce para a semana santa, em Braga;

ix. as feiras francas tradicionais, a primeira das quais é, incontornavelmente, a feira semanal de Barcelos;

x. os festivais de música moderna, com Paredes de Coura à cabeça, retomando a iniciativa pioneira de Vilar de Mouros;

xi....

Não se pense, no entanto, que mesmo no Minho não há custos decorrentes da crise sanitária. $\mathrm{Na}$ verdade, do que conheço no terreno, particularmente da vivência de Ponte de Lima, que tinha uma aposta turística bastante consistente (e é, um dos lugares atravessados pelo Caminho [Central] de Santiago e de outras "peregrinações", nomeadamente de natureza gastronómica e ambiental), fica patente que os custos são notórios. Ponte de Lima, digo, é o exemplo de um local onde foram feitos investimentos que não vão ser rendibilizados e onde há empregos que não serão recuperados nos curto e médio prazos.

Note-se a propósito que já antes da crise sanitária e pese o afluxo crescente de visitantes, era razoavelmente óbvio que a oferta de unidades de alojamento local estava a crescer muito acima das necessidades. Criou-se a ilusão de que havia espaço para todos e a rendibilidade gerada era elevada, o que estava longe da realidade. Muitas dessas unidades não vão voltar a abrir e outro tanto se passa com uma série de 
pequenos negócios que giravam em torno do turismo, nomeadamente de venda de artesanato, "lembranças de viagem" e restauração.

Esta é uma realidade que extravasa muito o caso de Ponte de Lima, mesmo no contexto do Minho. No caso de outros territórios que viveram mais intensamente o fenómeno da explosão do turismo em Portugal, a situação será muito mais grave. Seja como for, acredita-se que há futuro para o turismo em Portugal, e também no Minho, em particular.

Para o país, no seu todo, e para o Minho, em particular, a crise sanitária atual deve ser aproveitada para refletir sobre as estratégias a prosseguir, com expressão nos produtos a disponibilizar e na qualidade do serviço a prestar ao visitante, na perspetiva de relançar o turismo e reposicioná-lo num trilho que, simultaneamente, dê resposta à sua procura em matéria de experiência turística e preocupaçóes em termos de segurança sanitária, e que, também, seja mais sustentável.

\section{CONSIDERAÇÕES FINAIS}

Recorrendo a dados estatísticos que vêm sendo divulgados sobre os efeitos da crise sanitária provocada pela COVID-19 e a uma revisão de literatura académica sobre a mesma, produziu-se neste capítulo uma reflexão sobre os parâmetros em que se tem estado a tecer esta crise, com particular atenção às expressões económica e turística da mesma. A preocupação que se exprime não se limita ao presente momento, posto que importa inquirir sobre o que possa vir a ser a respetiva superação, como e quando.

Nesta perspetiva de equacionar a respetiva superação, crises sanitárias enfrentadas precedentemente podem fornecer ensinamentos importantes não só sobre os efeitos que tiveram, mas, também, que respostas foram encontradas e o tempo que demoraram a ser ultrapassadas.

Uma crise é sempre um momento de perturbação, de perda (humana, económica e outras) mas é, igualmente, uma oportunidade para instituir um novo começo, que pode apresentar graus variados de mudança face à trajetória precedente e, a essa luz, criar condiçốes para criar resiliência a potenciais fenómenos similares futuros. Nessa perspetiva, a atual crise constitui uma oportunidade para reinventar o turismo de 
amanhã, que tem que caminhar na direção de uma oferta mais sustentável, resiliente e inovadora, no sentido de singular.

Nesta leitura de situação e perspetivação do horizonte, recusa-se a ideia de que o turismo não pode/não deve continuar a ser um setor estruturante da economia portuguesa. No entanto, tal não é igual a dizer que deve ser "o setor estruturante”. Claramente, há que equacionar a estratégia de desenvolvimento turístico seguida em Portugal, o que a crise da COVID-19 torna mais patente, mas o caminho não será "abandonar" a aposta no turismo, mas reconfigurá-la, dar-lhe maior sustentabilidade e focá-la em produtos que aportem mais valor e sejam dotados de maior singularidade.

Pela oferta de que dispóe em várias áreas, Portugal pode estruturar pacotes que conjuguem turismo cultural, turismo natural, turismo de bem-estar e turismo ativo e criativo para atrair visitantes exigentes em matéria de experiência turística e, no contexto imediato, ansiosos por recuperarem do período de confinamento a que estiveram sujeitos por força da crise sanitária. Desse ponto de vista, parece fazer sentido apostar na promoção do património natural e dos espaços de baixa densidade populacional como alternativas, pois representam baixos riscos de contaminação e a gestão de grupos é mais fácil. A ideia é, obviamente, promover Portugal como destino seguro do ponto de vista de cuidados com a propagação do vírus, mas tal não é suficiente.

A essa luz, o Minho sugere-se particularmente bem posicionado, não só por não se ter tornado um destino massificado no período pré-COVID-19 mas, também, porque muita da sua oferta potencial encaixa bem na estratégia que se entende ser necessário implementar no recomeço que importa fazer. As expressões culturais diversas e originais, a natureza, as manifestaçóes concretas do espaço rural, a gastronomia e vinhos, as rotas de peregrinação e de fruição da natureza constituem um potencial capaz de sustentar um desenvolvimento turístico rico em experiência e promotor de desenvolvimento local/regional. A esse potencial turístico importa que se junte garantia de segurança sanitária, qualidade de serviço e ofertas ativas e criativas, bebendo nos recursos e competências do território.

Como o desenvolvimento do fenómeno em estudo está em curso, com expressões no tempo e alcance que não podem ser antecipadas, a reflexão que é feita 
suporta-se em dados estatísticos que foram sendo quotidianamente divulgados, na vivência pessoal do autor, em informação divulgada na comunicação social de massas e em referências bibliográficas (artigos académicos) que, numa grande parte, não foram ainda publicados em periódicos científicos. A opção tomada sugere-se óbvia e inultrapassável posto que ainda não há um número significativo de trabalhos publicados sobre o impacte no turismo e na economia, em termos gerais, da COVID-19.

\section{REFERÊNCIAS}

Begley, S. (2013). Flu-Conomics: The Next Pandemic Could Trigger Global Recession. Disponível em https:// www.reuters.com/article/us-reutersmagazine-davos-flu-economy/flu-conomics-the-next-pandemic-couldtrigger-global-recession-idUSBRE90K0F820130121 (acesso em 2020/04/01).

Folinas, S. e Metaxas, T. (2020). “Tourism: The Great Patient of Coronavirus COVID-2019”. International Journal of Advanced Research, 8(04), 365-375. https://doi.org/10.21474/IJAR01/10788.

GEE (2020). Sintese Estatistica de Conjuntura/Short-term Economic Indicators, № 20/2020. Lisboa: Gabinete de Estratégia e Estudos, Ministério da Economia, 15 de maio de 2020.

Gössling, S., Scott, D. e Hall, M. (2020). "Pandemics, tourism and global change: a rapid assessment of COVID-19”. Journal of Sustainable Tourism, https://doi.org/10.1080/09669582.2020.1758708.

Hall, M., Scott, D. e Gössling, S. (2020). "Pandemics, transformations and tourism: be careful what you wish for”. Tourism Geographies, http://doi.org/10.1080/14616688.2020.1759131.

INE (2020a). Destaque: Atividade Turística - Março de 2020. Lisboa: Instituto Nacional de Estatística, 15 de maio de 2020.

INE (2020b). Destaque: Atividade Turística - Abril de 2020 - Estimativa rápida. Lisboa: Instituto Nacional de Estatística, 29 de maio de 2020.

Ioannides, D. e Gyimóthy, S. (2020): “The COVID-19 crisis as an opportunity for escaping the unsustainable global tourism path”. Tourism Geographies, http://doi.org/10.1080/14616688.2020.1763445.

Nunes, S. (2020). “Tourism and Innovation: towards a territorial symbiosis in the post-COVID-19”. Working Papers Series, N. 2020.01 (first draft, 04.05.2020). Tomar: CIAEGT- IPT, Instituto Politécnico de Tomar.

Olivié, I. e Gracia, M. (2020). "The end of globalisation? A reflection on the effects of the COVID-19 crisis using the Elcano Global Presence Index”. ARI 60/2020 (English version). Madrid: Elcano Royal Institute, 4 de maio de 2020. 
Público (2020). Onde ir depois disto tudo? Açores e Arrábida em top internacional de viajantes para o póspandemia. Seção Fugas, Público, 2020/03/28. Disponível em: https://www.publico.pt/2020/03/28/fugas/ noticia/onde-ir-acores-arrabida-top-internacional-viajantes-pospandemia-1909843 (acesso em 2020/05/24).

Ranasinghe, R., Karunarathna, C. e Pradeepamali, J. (2020). After Corona (COVID-19) Impacts on Global Poverty and Recovery of Tourism Based Service Economies: An Appraisal. Department of Tourism Studies, Uva Wellassa University of Sri Lanka. Preprint, May 2020 http://doi.org/10.13140/RG.2.2.26187.34087 (acesso em 2020/05/18).

RTBF.be (2020). Reprise du tourisme : le Portugal et la Grèce seront les destinations privilégiées. 16 de maio de 2020. Disponível em https://www.rtbf.be/tendance/voyage/destinations/detail_reprise-du-tourisme-leportugal-et-la-grece-seront-les-destinations-privilegiees?id=10502775 (acesso em 2020/05/19).

Ruiz Estrada, M., Park, D. e Lee, M. (2020). "How A Massive Contagious Infectious Diseases can Affect Tourism, International Trade, Air Transportation, and Electricity Consumption? The Case of 2019 novel coronavirus (2019-nCoV) in China”. SSRN Electronic Journal. http://doi.org/10.2139/ssrn.3540667.

Soares, J., Gabriel, L. e Romo, R. (Coord.) (2020). Impacto da COVID-19 no comportamento do turista brasileiro. Fortaleza, Ceará: Editora da Universidade Estadual do Ceará - EdUECE.

Turismo de Portugal (2017). Estratégia Turismo 2027. Lisboa: Turismo de Portugal I.P. (TdP), Ministério da Economia.

UNWTO (2020a). Global and Regional Tourism Performance. World Tourism Organization: https://www. unwto.org/global-and-regional-tourism-performance (acesso em 2020/05/05).

UNWTO (2020b). Las Llegadas de Turistas Internacionales Podrian Caer un 20-30\% en 2020. Organización Mundial del Turismo: https://www.unwto.org/es/news/omt-las-llegadas-de-turistas-internacionales-podriancaer-2020 (acesso em 2020/05/05).

ZAP aeiou (2020). COVID-19 não trava férias de verão. Reservas de casas e hotéis no Algarve aumentam. ZAP aeiou: http://www.aeiou.pt/, edição de 27 de abril de 2020 (acesso em 2020/04/27).

Zeng, B., Carter, R. e De Lacy, T. (2005). "Short-term perturbations and tourism effects: The case of SARS in China”. Current Issues in Tourism, 8(4), 306-322.

Wanjala, K. (2020). "Economic Impact Assessment of the Novel Coronavirus on Tourism and Trade in Kenya: Lessons from Preceding Epidemics”. Finance \& Economics Review, 2(1), 1-10. http://doi.org/10.38157/ finance-economics-review.v2i1.57. 